\title{
Reactive Power Support in Radial Distribution Network Using Mine Blast Algorithm
}

\author{
Mohsin Shahzad $^{1,}$, , Qazi Shafiullah', Waseem Akram ${ }^{1}$, Muhammad Arif ${ }^{1}$, Barkat Ullah ${ }^{2}$ \\ ${ }^{I}$ Department of Electrical and Computer Engineering, COMSATS University Islamabad, \\ Abbottabad Campus, Pakistan \\ ${ }^{2}$ Department of Mechanical Engineering, COMSATS University Islamabad, \\ Wah Campus, Pakistan \\ mohsinshahzad@cuiatd.edu.pk
}

\begin{abstract}
The passive power distribution networks are prone to imperfect voltage profile and higher power losses, especially at the far end of long feeders. The capacitor placement is studied in this article using a novel Mine Blast Algorithm (MBA). The voltage profile improvement and reduction in the net annual cost are also considered along with minimizing the power loss. The optimization problem is formulated and solved in two steps. Firstly, the Voltage Stability Index (VSI) is used to rank the nodes for placement of the capacitors. Secondly, from the priority list of nodes in the previous step, the MBA is utilized to provide the optimal location and sizes of the capacitors ensuring loss minimization, voltage profile improvement, and reduced net annual cost. Finally, the results are tested on 33 and 69 radial node systems in MATLAB. The results for the considered variables are presented which show a significant improvement in active and reactive power loss reduction and voltage profile with lesser reactive power injection.
\end{abstract}

Index Terms-Capacitor placement; Distribution system; Loss mitigation; Mine Blast Algorithm; Voltage stability.

\section{INTRODUCTION}

The conventional power system enables the energy flow at the longer electrical distance leading to excessive power losses. About $13 \%$ of the losses in electrical power system occur at distribution systems [1]. A considerable contributing factor in these losses is the excessive reactive power demand at the distribution level, which negatively impacts the voltage profile of the system [2]. To protect the significant amount of power from wastage in the form of electrical losses, various methods, including Synchronous Condenser (SC) [3], Distribution Generation (DG) [4], FACTS devices [5], and capacitor placement [2], have been widely studied.

The SCs are considered to be the very mature and well understood technology for reactive power compensation. Nevertheless, the synchronous condensers are hardly utilized nowadays since they need a significant amount of starting and protection gears. In addition, they cannot be modified rapidly enough to accommodate the rapid load changes [6]. In recent years, DGs have been extensively penetrated into the distribution network, which can provide additional benefits of loss minimization, reactive power

Manuscript received 9 March, 2021; accepted 4 June, 2021. support, and voltage profile improvement. However, as the conventional distribution systems are designed for unidirectional power flow, DGs can pose a challenge of reverse power flow [7]. The FACTs are attributed as additional damping schemes used to enhance the controllability and power transfer capability of power system. However, they may not be able to achieve the fast and sufficient damping over the oscillations [8].

The capacitor banks in the electric distribution system are widely utilized due to the fact that they are more reliable and economical than previously discussed technologies [9]. The advantages of installing capacitors are the improvement of the systems voltage profile, power factor, the reduction of power loss, reduced reactive power demand from main grid, and the boost in available feeder capacity. Additionally, the capacitor banks can help in reducing the voltage fluctuations resulting due to the operation of some DG types. Moreover, to maximize the benefits and utilization, the optimally sized capacitors should be placed at optimal locations. [2]. Improper placement of the capacitor results in even higher system losses and voltage drops [10]. The problem of optimal capacitor allocation attempts to determine the location, size, and the number of capacitor banks to be installed such that the maximum economics can be obtained without breaching the operational constraints [11].

\section{RELATED WORKS}

Several recent studies, based upon various computational techniques, have been concentrated on the capacitor banks placement in the power distribution systems. The available strategies are categorized as numerical programming, analytical, artificial intelligence, and heuristic algorithm [12]. A few authors proposed the classical methods based capacitors allocation with the loss reduction in a power system as the main objective [13], [14]. The classical approaches have the drawbacks, such as difficulty in escaping local minima and trouble in handling discrete control variables [15].

The optimal capacitor placement problem is a combinatorial problem; hence utilization of the modern heuristic methods has got more attention. In [16], the simulated annealing (SA) based optimal capacitor allocation is proposed. This approach is prone to trapping at a local 
optima leading to the possibility of inaccurate prediction of the optimum cost. In [17], the capacitor allocation problem is solved through Tabu Search (TS). Despite the fact that TS appears to be successful for the design problem, the use of complicated objective functions, as well as a large number of optimization parameters, decreases the performance of the algorithm. In [18], the Genetic Algorithm (GA) is proposed for optimum allocation and rating of the capacitors, but it takes a long time based on the size of the network. In [19], the Particle Swarm Optimization (PSO) is implemented; however, it tends to suffer from slow convergence in the search stage, poor local search capability, and it may trap in a local minima.

In [20], the capacitive compensation is done through the Direct Search Algorithm (DSA), however, this study does not consider the maintenance and installation cost for the capacitor banks. The Plant Growth Simulation Algorithm (PGSA) [21] and the Cuckoo Search Algorithm (CSA) [22], [23] are proposed for the problem of the capacitor placement in the power network. Although these methods have produced good results, instead of discrete indices, continuous values of the capacitors were used, which lead to giving the unavailable sizes of the capacitors. In [23], to control the size of the search space, the problem was split into two subparts and used the Loss Sensitivity Factors (LSF) to locate optimal locations. In this way, the speed increased at the cost of accuracy. In [24], the Artificial Bee Colony $(\mathrm{ABC})$ is presented for solving the same issue, however, the convergence is very slow. In [25], another method, namely, cuckoo search is proposed for the allocation of the capacitor; however, it takes a long time and a large number of iterations to obtain the optimal solution. The Ant Colony Optimization (ACO) [25] is presented for the same issue, however, the theoretical calculations are difficult, and with the iteration, its probability distribution changes. In [26], the Firefly Algorithm (FA) and LSF based optimal capacitor placement is done. This method did not consider the power loss cost and the reduced accuracy because of the split algorithm. The Harmony Search (HS) [27] is implemented for the problem of the capacitor allocation. However, good results came from it; the cost for the power losses is considered as the objective function only and the installation and operating costs are ignored.

A population based metaheuristic algorithm based on the explosion of a mine bomb concept called "Mine Blast Algorithm" (MBA) is proposed in [28]. The effectiveness and superiority of the MBA are studied in several engineering problems in terms of function evaluation and found better than contemporary methods [28]. As discussed earlier, the recent approaches are unable to cater for the optimal installation and operation costs of the capacitor banks.

The major contributions in this paper are to reduce both the active and the reactive power loss, thereby improving the voltage profile of the network along with reducing the total annual cost for installation and operation of the capacitor banks. At first, the locations for the placement of the capacitors are examined and arranged on the basis of the Voltage Stability Index (VSI) [29]. Afterwards, the MBA is implemented to determine the optimum sizes and locations for the capacitors placement from the VSI based arranged nodes. It is pertinent to highlight that the proposed method only arranges nodes on the basis of VSI which is unlike the selection based on the LSF as done in [25], [26]. The sorting of the nodes on the basis of VSI is preferred over LSF because the reactive power injection is closely related to the voltage stability as compared to the losses. The proposed method is implemented in MATLAB and the results are validated on the standard IEEE 33 and 69 node networks. To observe the effectiveness of the proposed work, the results are compared with other algorithms, namely, Strawberry Plant Propagation Algorithm (SPPA) [4], [30], Genetic Moth Swarm Algorithm (GMSA) [31], and Flower Pollination Algorithm (FPA) [32].

The rest of the article is organized as follows. Section III explains the problem formulation. In Section IV, the implementation strategy is explained. This section contains details of the methods and methodology, including VSI, MBA, and complete set of steps for implementation. The results and respective discussion are provided in Section $\mathrm{V}$. This section also details the voltage quality index used in this work to quantify the improvement in the voltage profile. Finally, the conclusions are given in Section VI.

\section{PROBLEM FormULATION}

\section{A. Total Power Loss}

The objective function of the optimal capacitor allocation problem is a subject to various constraints. In this work, the improvement in voltage profile and the reduction in net annual cost are considered by reducing the active and reactive power loss in the network. The major objective for the optimal allocation of the capacitors in a radial distribution network is to mitigate the total power losses [33], (1) while satisfying all the operational constraints

$$
P_{\text {loss }}=\Sigma_{j=1}^{n} I_{j}^{2} Z_{j},
$$

where $P_{\text {loss }}$ : the total power losses in each branch, $n:$ the total number of branches, $I_{j}$ : the current on line, $j$ and $Z_{j}$ : the impedance of line $j$. The power loss minimization problem is defined as

$$
\text { minimize } \quad P_{\text {loss }}
$$

subject to the following constraints:

$$
\begin{gathered}
V_{\text {min }} \leq\left|V_{i}\right| \leq V_{\text {max }}, \\
S_{j} \leq S_{j, \text { max }}, \\
Q_{C \text { total }} \leq Q_{\text {Dtotal }}, \\
\left|I_{j}\right| \leq I_{\text {max }},
\end{gathered}
$$

where $V_{\min }$ and $V_{\text {max }}$ : the minimum and the maximum voltage at node $i$, respectively, $S_{j, \max }$ is the maximum allowable power flow over the line $j$, respectively, $Q_{C \text { total }}$ and $Q_{\text {Dtotal }}$ are the injected reactive power by the installed 
capacitors and the total reactive power demand of the network, respectively, and $I_{\max }$ is the maximum allowable current flowing over line $j$.

\section{B. Total Annual Active Power Loss Cost}

The total annual active power loss cost $(\mathrm{N})$ measured in \$/year given by (7) [34] is also studied after optimal capacitors placement

$$
N=K_{p} P_{\text {rloss }} T+D\left(K_{1} C B+K_{c} \Sigma_{i}^{C B} K_{c_{i}}\right)+K_{o} C B
$$

where $K_{p}:$ cost $/ \mathrm{kWh}, P_{\text {rloss }}:$ active power loss, $T:$ time in hours, $D$ : depreciation factor, $K_{1}$ : cost of installation, $C_{B}$ : number of capacitor banks, $K_{C}:$ cost/kVAR, $K_{o}$ : operating cost. The values considered for these variables are summarized in Table I [34]. The net saving (\$/year) is calculated by taking difference of the annual cost with and without the reactive power compensation.

\begin{tabular}{|c|c|} 
TABLE I. USED PARAMETERS. \\
\begin{tabular}{|c|c|}
\hline$K_{p}=\$ 0.06 / \mathrm{kWh}$ & $K_{c}=\$ 25 / \mathrm{kV} \mathrm{Ar}$ \\
\hline$T=8760 \mathrm{~h}$ & $K_{o}=300 \$ /$ year $/$ location \\
\hline$D=0.2$ & $K_{1}=1600 \$$ \\
\hline
\end{tabular}
\end{tabular}

\section{IMPLEMENTED STRATEGY}

The main objective of this work is to locate the optimal location(s) and size(s) of capacitor(s) in to ensure minimum loss operation, while maintaining the system under the suitable operation limit. The problem has two parts; the location selection, which is from a limited number of nodes in the network, and the size of capacitor(s) for the selected node(s) in the former part which will be a continuous variable. Keeping in view the nature of the problem, it is split into two parts. Firstly, the nodes are ranked according to the VSI [35]. In a large distributed network, the algorithm have to search for optimal location by inspecting every node for the candidate location. This increases the evaluation time in finding the optimal solution. Hence, due to VSI, the search decreases due to this initial estimation of candidate nodes. Secondly, the optimization algorithm is utilized to locate the optimal node from the selected candidate nodes in the former part and find the appropriate size(s) of the capacitor(s) to be placed.

\section{A. Voltage Stability Index (VSI)}

The degree of voltage stability of the networks can be calculated using the VSI which identifies the most vulnerable node as the candidate location for the allocation of the capacitor in the power system [35]. The search space in the implemented optimization algorithm is significantly reduced by this initial estimation of candidate nodes.

Consider a two-node equivalent system having line impedance of $R(j)+j X(j)$ and a load of $P\left(m_{2}\right)+j Q\left(m_{2}\right)$ connected to node $m_{2}$ as shown in Fig. 1.

The VSI is given as

$$
\operatorname{VSI}\left(m_{2}\right)=\left|V\left(m_{1}\right)\right|^{4}-4\left[P\left(m_{2}\right) X(j)-\right.
$$

$$
\left.-Q\left(m_{2}\right) R(j)\right]^{2}-4\left[P\left(m_{2}\right) R(j)+Q\left(m_{2}\right) X(j)\right],
$$

where $\operatorname{VSI}\left(m_{2}\right):$ the voltage stability index for node $m_{2}$ $\left(m_{2}=2,3, \ldots, n\right), n:$ the total number of nodes, $j:$ the branch number, $V\left(m_{1}\right)$ : the voltage magnitude on node $m_{1}$. The node with the least VSI value is the most vulnerable to voltage breakdown and becomes most suitable for the placement of appropriately sized capacitor.

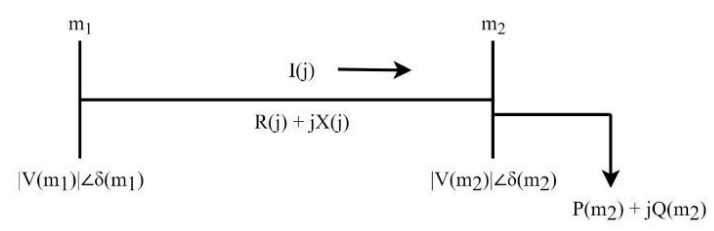

Fig. 1. Simple distribution line.

\section{B. Mine Blast Algorithm (MBA)}

Sadollah, Bahreininejad, Eskandar, and Hamdi developed a population-based mine bomb explosion-inspired optimizer called "Mine Blast Algorithm" (MBA) [28]. The idea behind the implemented algorithm is based on the observance of a mine bomb explosion, in which the scattered fragments from the mine bomb collide with many other mine bombs in the vicinity of the explosion, resulting in their explosions [36]. To better understand the condition, consider a minefield for which the primary goal is to clear up the minefield from mines. The objective, therefore, is to locate the explosive mines, whilst it is necessary to locate the most explosive one placed at the optimum location $\mathrm{X}^{*}$, which may create the maximum casualties.

The algorithm begins via an initial value termed as a first shot point $X_{0}^{f}$. The $f$ in the superscript indicates the first shot point numbers, i.e., $(f=1,2,3, \ldots)$. Nevertheless, the algorithm selects the location arbitrarily within the given lower and upper limits of the problem. The population is generated by the $1^{\text {st }}$ shot explosion which produces several pieces of shrapnel. Just like the other algorithms, this algorithm as well requires an initial population. The initial population $\left(N_{\text {pop }}\right)$ is considered to be the number of pieces of shrapnel $\left(N_{s}\right)$.

The explosion of mine bomb produces shrapnel pieces causing another mine bomb to explode at $X_{n+1}$

$$
X_{n+1}^{f}=X_{e(n+1)}^{f}+\exp \left(-\sqrt{\frac{m_{n+1}^{f}}{d_{n+1}^{f}}}\right) X_{n}^{f}, n=0,1,2, \ldots,
$$

where $X_{n+1}^{f}, d_{n+1}^{f}$, and $m_{n+1}^{f}$ are the mine bomb location exploded by the collision of shrapnel bits, distance, and direction of the shrapnel pieces tossed for each iteration, respectively. Location of new exploited mine is

$$
X_{e(n+1)}^{f}=d_{n+1}^{f} \times \operatorname{rand} \times \cos \left(\frac{360}{N_{s}}\right), n=0,1,2, \ldots .
$$

For exploring a new location, an exploration factor $(\mu)$ is initiated. The $\mu$ factor is used during the initial iterations of 
the algorithm which is then compared to the iteration value $k$. If the value is greater than iteration value $k$, the exploration process starts. The equations used to explore the solution search space are as:

$$
\begin{gathered}
d_{n+1}^{f}=d_{n}^{f} \times|\operatorname{randn}|^{2}, n=0,1,2, \ldots, \\
X_{e(n+1)}^{f}=d_{n+1}^{f} \times \cos \left(\frac{360}{N_{s}}\right), \quad n=0,1,2, \ldots
\end{gathered}
$$

The direction and the distance of shrapnel pieces in the exploitation process are given as:

$$
\begin{aligned}
& d_{n+1}^{f}=\sqrt{\left(X_{n+1}^{f}-X_{n}^{f}\right)+\left(F_{n+1}^{f}+F_{n}^{f}\right)^{2}}, \\
& n=0,1,2, \ldots, \\
& m_{n+1}^{f}=\frac{F_{n+1}^{f}+F_{n}^{f}}{X_{n+1}^{f}-X_{n}^{f}}, \quad n=0,1,2, \ldots
\end{aligned}
$$

where $F$ at location $t+1$ represents the fitness function. The ability of global search is increased when the initial distance of the shrapnel pieces is gradually reduced to enable mine bombs to search for a likely global minimal location. The $\alpha$ being a user parameter is introduced to achieve a convergent optimized solution. The distance is formulated as

$$
d_{n}^{f}=\frac{d_{n+1}^{f}}{\exp (k / \alpha)}, \quad n=0,1,2, \ldots
$$

At the last iteration, the shrapnel pieces distance value will be approximately zero. The schematic figure of the implemented algorithm portrays two aspects (the colour lines indicate the exploring process and the black colour lines are the exploitation process, see Fig. 2).

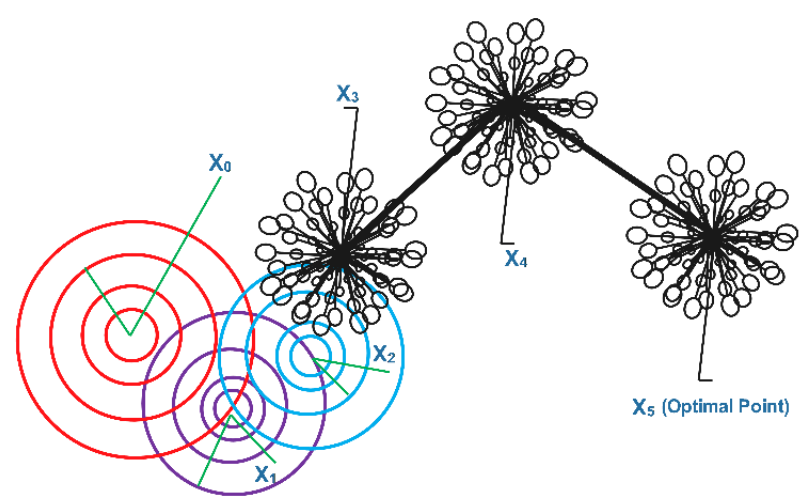

Fig. 2. Schematic view of processes for the MBA [37].

\section{Steps of Implemented Methodology}

1. Read the system input data and run the base case load flow.

2. Calculate VSI of every node and rank the nodes in the ascending order according to the VSI.

3. Impose limit on the number of nodes to be considered for the capacitor placement, i.e., set value of "nvar". In this study, top ten nodes in the VSI list developed in step 2 are considered.
4. Set the upper and lower limits of the problem, i.e., capacitor sizes (according to reactive power injection) to be considered for placement by the algorithm. The range of $0 \mathrm{MVar}-1.5 \mathrm{MVar}$ is taken in this work.

5. Initialize the algorithm by setting the iteration count, population size, exploration, and reduction factors.

6 . Check the exploration factor $(\mu)$ condition.

7. If the condition of the exploration factor is met, i.e., $\mu$ > iter, then:

- Calculate the location of a piece, i.e., node in the network using (12);

- Calculate the distance of a shrapnel piece, i.e., capacitor size according to (11) at the respective location;

- Calculate the direction of pieces using (14);

- Calculate the fitness function in terms of loss.

8. Evaluate function value for any improvements.

9. If improved, swap the shrapnel piece's position with the finest temporal solution. If not, go to step 12 .

10. Save the finest piece of shrapnel, i.e., capacitor size as the best temporary solution.

11. If $\mu>$ iter, then generate the shrapnel pieces for the exploitation process.

12. Calculate the distance and location, i.e., capacitor size and node, respectively.

- Using (10), calculate the location.

- Calculate the distance of pieces using (13).

- Inspect the parameters of the constraint for the generated pieces of shrapnel.

13. Adaptively reduce the distance of shrapnel pieces, i.e., search the area for capacitor sizes using (15).

14. Analyse the criteria for convergence. If true, then End else, go to step 6.

\section{RESUlTS AND DisCUSSION}

To assess the efficiency of the proposed method for the optimal allocation and sizing of capacitors, the two standard radial distribution networks, i.e., 33-node and 69-node are used for the test bench. The implementation of the MBA is done in MATLAB. The results are compared for the voltage levels on the nodes in the network, total active and reactive power losses and annual cost and net savings. To better quantify the improvement in the voltage profile, the voltage quality index (VQI) [37] of the network is also calculated as

$$
V Q I=\left[V_{\text {nom }}-\frac{V_{\max }-V_{\min }}{V_{\max }}\right] 100 \%,
$$

where $V_{\text {nom }}$ denotes the nominal voltage magnitude in p.u., which is considered to be unity in this case. $V_{\max }$ and $V_{\text {min }}$ denotes the maximum and the minimum value of the voltage on a particular node in the power network.

\section{A. 33-Node Network}

In the first case, the standard IEEE-33 node system is used. The line and node details are taken from [38]. It comprises of 32 nodes and 5 tie lines. The total substation active and reactive power loads are 3.7 MW and 2.3 MVar, respectively. All the measurements are done in per-unit 
system. The base values of $100 \mathrm{MVA}$ and $12.66 \mathrm{kV}$ are considered in this implementation. The test system in single line diagram is displayed in Fig. 3.

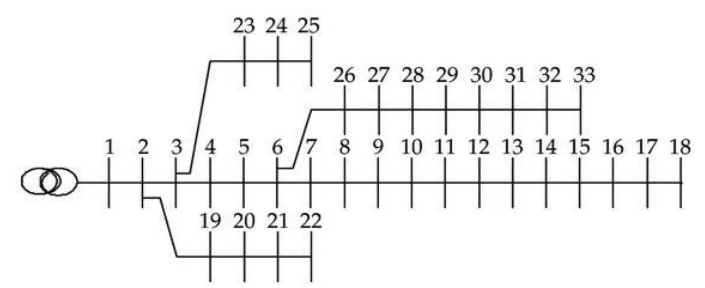

Fig. 3. IEEE-33 Node system single line diagram.

The radial distribution network has heavy inductive loads that cause the low voltages on the nodes. This low voltage can be enhanced by integrating the capacitors to the nodes that deliver a portion of the reactive power consumed by the load, thus reducing the flow of the current and losses. The active and reactive power loss for the base case (before compensation) are $208.18 \mathrm{~kW}$ and $138.9 \mathrm{kVAR}$, respectively.

After implementing the MBA, the losses are considerably decreased due to placing the appropriately sized capacitor(s) at the optimal location(s). Figure 4 highlights the reduction in active power loss over individual branches, which accumulates to about $34.13 \%$ with MBA (see Table II). The figure also shows that the MBA produced better results than SPPA. The loss reduction with SPPA is approximately $29.9 \%$ of the base case losses.

The reduction for reactive power losses in the network with MBA and SPPA are compared with the base case and are shown in Fig. 5. It is observed that the reduction of the reactive power losses from the base case with MBA is $33.69 \%$ and with SPPA is $27.4 \%$ in comparison to the base case as detailed in Table II.

TABLE II. COMPARISON RESULTS OF THE 33-NODE SYSTEM.

\begin{tabular}{|c|c|c|c|c|c|}
\hline \multirow{3}{*}{\begin{tabular}{|c|} 
Items \\
Optimal size \\
kVAR (node No.) \\
\end{tabular}} & \multirow{3}{*}{\begin{tabular}{|l|} 
Base Case \\
\end{tabular}} & \multicolumn{4}{|c|}{ Compensated } \\
\hline & & GMSA & FPA & SPPA & MBA \\
\hline & & $\begin{array}{c}150(2) \\
450(12) \\
900(18) \\
450(24) \\
1050(30)\end{array}$ & $\begin{array}{l}900(30) \\
450(13) \\
450(24)\end{array}$ & \begin{tabular}{|c|}
$87(18)$ \\
$245(17)$ \\
$697(33)$ \\
$444(32)$ \\
$185(16)$
\end{tabular} & $\begin{array}{l}160(17) \\
303(33) \\
228(14) \\
992(30)\end{array}$ \\
\hline $\begin{array}{c}\text { Total injected } \\
\text { Vars } \\
(\text { kVAR) } \\
\end{array}$ & - & 3000 & 1800 & 1658 & 1683 \\
\hline Ploss (kW) & 208.2 & 135.4 & 137.2 & 145.9 & 135.8 \\
\hline $\begin{array}{c}\text { Ploss Reduction } \\
(\%)\end{array}$ & - & 35.03 & 34.79 & 29.9 & 34.41 \\
\hline Qloss (kVAR) & 138.9 & N/A & N/A & 100.83 & 90.71 \\
\hline $\begin{array}{c}\text { Qloss Reduction } \\
(\%)\end{array}$ & - & N/A & N/A & 27.39 & 34.69 \\
\hline Vmin (p.u) & 0.9125 & 0.9343 & 0.9327 & 0.9461 & 0.9405 \\
\hline $\begin{array}{c}\text { Total injected } \\
\text { Vars } \\
\text { cost }(\$)\end{array}$ & - & 75000 & 45000 & 41438 & 42080 \\
\hline Annual cost $(\$ / y r)$ & 109419 & 89256 & 82988 & 88083 & 82277 \\
\hline Net saving $(\$ / y r)$ & - & 20164 & 26431 & 21336 & 27142 \\
\hline Saving (\%) & - & 18.43 & 24.15 & 19.5 & 24.81 \\
\hline VQI (\%) & 91.25 & 93.43 & 93.27 & 94.61 & 94.05 \\
\hline
\end{tabular}

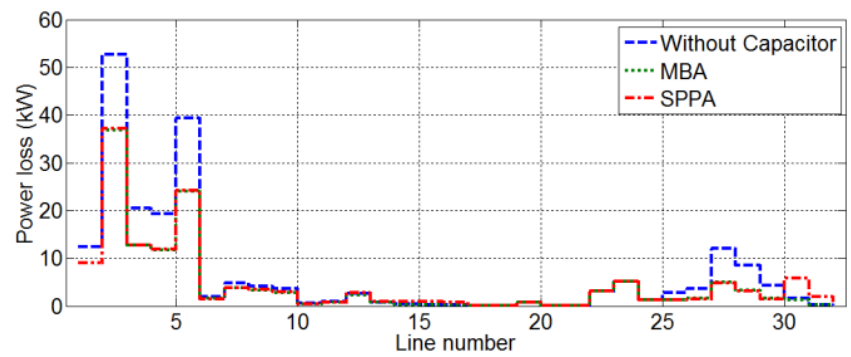

Fig. 4. IEEE-33 node system active power loss.

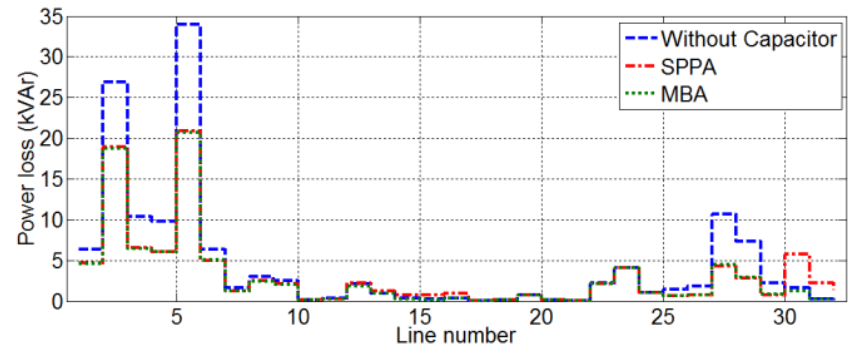

Fig. 5. IEEE-33 node system reactive power loss.

The comparison of the voltage levels for the base case with MBA and SPPA is shown in Fig. 6. In this study, the external grid is connected to node 1 , which is considered as the reference and the voltage at it is taken to be 1 p.u. The least value of the voltage in the base case occurs at node 18 , i.e., 0.9125 p.u as shown in Table II. After the capacitor placement with MBA, the voltage profile improved significantly and the minimum voltage is observed at node 18, i.e., 0.9405 p.u., which is slightly less than 0.9461 p.u at node 14 obtained from SPPA.

The detailed information of optimal location, optimal size, power losses and the minimum voltage for different algorithms is summarized in Table II. It can be seen that the yearly net cost after implementing MBA is reduced from 109419 \$ to 82277.3 \$ which counts to a percentage saving of $24.81 \%$. Table II also highlights the effectiveness of MBA in comparison to the GMSA, FPA and SPPA in terms of different variables under consideration, despite injecting lesser amount of reactive power (Vars). The total injected Vars by MBA are 1683.2 kVAR that is significantly lesser than the likes of GMSA with $3000 \mathrm{kVAR}$, FPA with $1800 \mathrm{kVAR}$ and SPPA with $1658 \mathrm{kVAR}$. Although the \% active power loss is very slightly better in case of GMSA and FPA than MBA, yet the injected Vars are higher and the minimum recorded voltage is lesser. The comparison of net saving and annual cost also speaks about the better performance with the MBA than any counterpart. It is also worth mentioning that the cost of installation of capacitors would also be lesser because the improved performance of the network in terms of losses and voltage profile were observed with lesser Vars injection with the proposed method, as depicted in Table II as cost of injected Vars.

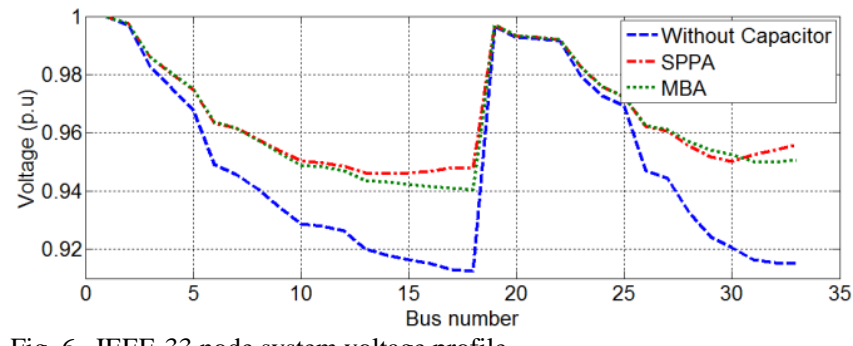

Fig. 6. IEEE-33 node system voltage profile. 


\section{B. 69-Node Network}

In this case, IEEE 69-node radial system is used. The system data is taken from [38]. The per-unit base ratings for the system are $12.7 \mathrm{kV}$ and $10 \mathrm{MVA}$. The test system is given as a single line diagram in Fig. 7. It has 68 nodes and one slack node. The total active and reactive loads are 3.8 MW and 2.7 MVar, respectively. Before compensation, the system's total active and reactive losses are $225 \mathrm{~kW}$ and 102.2 kVAR, respectively whereas the annual power loss cost is calculated to be $118260 \$$.

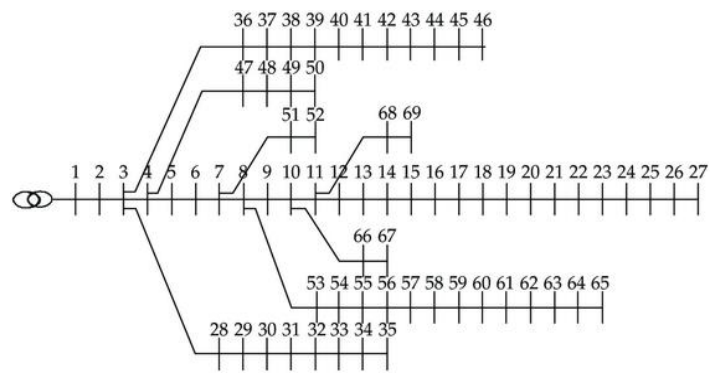

Fig. 7. IEEE-69 node system single line diagram.

The reduction in active power loss before and after the optimal capacitor placement with MBA and SPPA can be seen in Fig. 8. In total, the loss reduction of $34.1 \%$ with MBA and $33.4 \%$ with SPPA is observed in comparison to the base case, as shown in Table III.

TABLE III. COMPARISON RESULTS OF THE 69-NODE SYSTEM.

\begin{tabular}{|c|c|c|c|c|c|}
\hline \multirow{2}{*}{$\begin{array}{c}\text { Items } \\
\text { Optimal size } \\
\text { kVAR (node No.) } \\
\end{array}$} & \multirow[t]{3}{*}{$\begin{array}{l}\text { Base } \\
\text { Case } \\
\end{array}$} & \multicolumn{4}{|c|}{ Compensated } \\
\hline & & GMSA & FPA & SPPA & MBA \\
\hline & & \begin{tabular}{|c|}
$750(2)$ \\
$300(12)$ \\
$450(50)$ \\
$900(61)$ \\
$350(64)$ \\
\end{tabular} & $\begin{array}{c}450(11) \\
1350(61) \\
150(22)\end{array}$ & \begin{tabular}{|l|}
$200(65)$ \\
$178(63)$ \\
$588(62)$ \\
$492(64)$ \\
$370(27)$ \\
\end{tabular} & $\begin{array}{l}318(63) \\
940(62) \\
208(64) \\
314(27)\end{array}$ \\
\hline $\begin{array}{c}\text { Total injected Vars } \\
(\mathrm{kVAR})\end{array}$ & - & 2750 & 1950 & 1828 & 1780 \\
\hline Ploss (kW) & 225 & 144.03 & 145.86 & 149.92 & 148.24 \\
\hline $\begin{array}{c}\text { Ploss Reduction } \\
(\%)\end{array}$ & - & 35.03 & 35.17 & 33.4 & 34.11 \\
\hline Qloss (kVAR) & 102.2 & N/A & N/A & 69.74 & 68.30 \\
\hline $\begin{array}{c}\text { Qloss Reduction } \\
(\%)\end{array}$ & - & N/A & N/A & 31.74 & 32.46 \\
\hline Vmin (p.u.) & 0.9092 & 0.9331 & 0.9330 & 0.9337 & 0.9320 \\
\hline $\begin{array}{c}\text { Total injected Vars } \\
\text { cost }(\$)\end{array}$ & - & 68750 & 48750 & 45675 & 44495 \\
\hline Annual cost (\$/yr) & 118260 & 92552 & 88274 & 91033 & 89294 \\
\hline Net saving $(\$ / y r)$ & - & 25708 & 29986 & 27227 & 28966 \\
\hline Saving (\%) & - & 21.74 & 25.4 & 23 & 24.5 \\
\hline VQI (\%) & 90.9 & 93.3 & 93.3 & 93.3 & 93.2 \\
\hline
\end{tabular}

In Fig. 9, the reduction of reactive power losses after implementing MBA and SPPA in comparison with the base case is given. There are $32.46 \%$ and $31.74 \%$ of reduction in reactive power loss after MBA and SPPA, respectively, as given in Table III.

Like before, node 1 is taken as a slack node having a maximum voltage of 1 p.u. Before compensation the lowest value of voltage, i.e., 0.91309 p.u. occurs at node 65 as shown in Table III. After compensation with MBA, the least voltage value of 0.9320 p.u. occurs at node 65 whereas with
SPPA the minimum voltage of 0.9337 occurs at node 64. It is noted that SPPA has a slightly better voltage value than MBA, however this is due to the fact that injected kVAR by SPPA is higher than that of later one. The implementation of MBA and SPPA, enhances the overall voltage profile of the network and is compared with the base case shown in Fig. 10 .

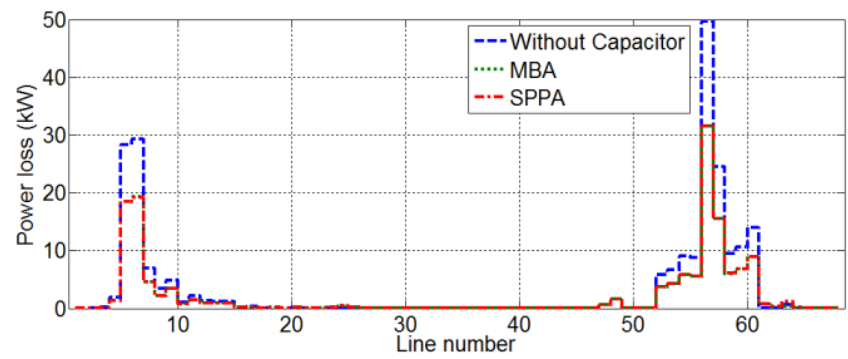

Fig. 8. IEEE-69 node system active power loss.

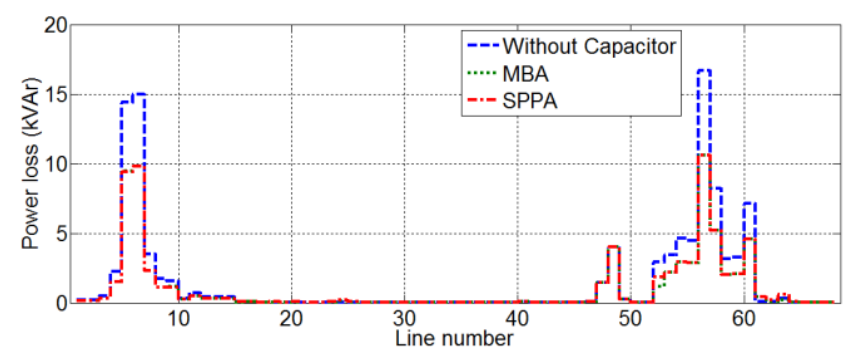

Fig. 9. IEEE-69 node system reactive power loss.

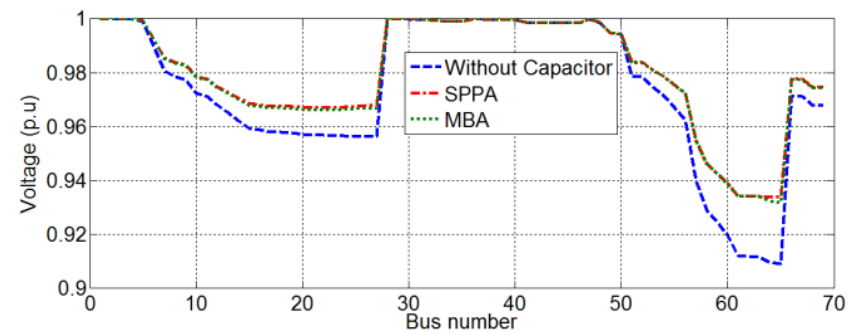

Fig. 10. IEEE-69 node system voltage profile.

In Table III, the detailed information of the optimal location, optimal size, power losses, and minimum voltage obtained from different algorithms is summarized. The effectiveness of the MBA is compared with GMSA, FPA, and SPPA in terms of considered variables. The yearly net cost after the placement of capacitors is reduced from 118260 \$ to 89294 \$, which gives the percentage saving of $24.5 \%$. The injected Vars by MBA is $1780 \mathrm{kVAR}$, i.e., significantly lesser than GMSA (2750 kVAR), FPA (1950 kVAR), and SPPA (1828 kVAR). Although the active power loss reduction given by the GMSA and FPA is slightly better than MBA, yet the injected Vars are higher and recorded lesser minimum voltage. The higher injected Vars also account for lesser \% saving. The better performance of MBA in terms of net saving and annual cost is shown in Table III as compared with other algorithms. In addition, the cost of the installation of capacitors with the proposed method is lesser as lesser Vars are injected, yet gives improved performance in terms of losses and voltage profile than the other counterparts.

\section{CONCLUSIONS}

The problem of the active and reactive power loss 
minimization in the radial distribution network is solved using the novel MBA subsequently improving the voltage profile and reducing the net cost. The initial sorting and selection of the nodes is done through voltage stability index (VSI). The results with MBA are compared to the results with SPPA, GMSA, and FPA in both of the considered networks. For 33-node network, the active and reactive power loss reduction is $34.13 \%$ and $33.69 \%$, respectively. Similarly, in 69-node network, the active and reactive power loss reduction is $34.1 \%$ and $32.46 \%$, respectively. The voltage quality index is improved after capacitor placement with MBA to $94.01 \%$ and $93.2 \%$ in 33- and 69-node networks, respectively. Despite improving results significantly, the total injected Vars with MBA are reduced leading to increased annual saving of $24.8 \%$ and $24.5 \%$ in 33 - and 69-node networks.

\section{CONFLICTS OF INTEREST}

The authors declare that they have no conflicts of interest.

\section{REFERENCES}

[1] T. T. Nguyen, B. H. Dinh, T. D. Pham, and T. T. Nguyen, "Active power loss reduction for radial distribution systems by placing capacitors and PV systems with geography location constraints", Sustainability, vol. $12, \quad$ no. $18, \quad$ p. 7806,2020 . DOI: $10.3390 /$ su12187806

[2] A. A. Abou El-Ela, R. A. El-Sehiemy, and A. S. Abbas, "Optimal placement and sizing of distributed generation and capacitor banks in distribution systems using water cycle algorithm", IEEE Systems Jour., vol. 12, no. 4, pp. 3629-3636, 2018. DOI 10.1109/JSYST.2018.2796847

[3] S. Kynev, G. Pilz, and H. Schmitt, "Comparison of modern STATCOM and synchronous condenser for power transmission systems", in Proc. of 2016 IEEE Electrical Power and Energy Conf. (EPEC), 2016, pp. 1-6. DOI: 10.1109/EPEC.2016.7771769.

[4] M. Shahzad, W. Akram, M. Arif, U. Khan, and B. Ullah, "Optimal siting and sizing of distributed generators by strawberry plant propagation algorithm", Energies, vol. 14, no. 6, p. 1744, 2021. DOI: 10.3390/en14061744.

[5] B. Ismail, N. I. A. Wahab, M. L. Othman, M. A. M. Radzi, K. N. Vijyakumar, and M. N. M. Naain, "Comprehensive review on optimal location and sizing of reactive power compensation using hybridbased approaches for power loss reduction, voltage stability improvement, voltage profile enhancement and loadability enhancement", IEEE Access, vol. 8, pp. 222733-222765, 2020. DOI: 10.1109/ACCESS.2020.3043297.

[6] V. A. V. Mohanan, I. M. Y. Mareels, R. J. Evans, and R. R. Kolluri, "Stabilising influence of a synchronous condenser in low inertia networks", IET Generation, Transmission \& Distribution, vol. 14, no. 17, pp. 3582-3593, 2020. DOI: 10.1049/iet-gtd.2020.0178.

[7] S. Kalambe and G. Agnihotri, "Loss minimization techniques used in distribution network: Bibliographical survey", Renewable Sustainable Energy Rev., vol. 29, pp. 184-200, 2014. DOI: 10.1016/j.rser.2013.08.075

[8] M. A. Hannan, N. N. Islam, A. Mohamed, M. S. H. Lipu, P. J. Ker, M. M. Rashid, and H. Shareef, "Artificial intelligent based damping controller optimization for the multi-machine power system: A review", IEEE Access, vol. 6, pp. 39574-39594, 2018. DOI: 10.1109/ACCESS.2018.2855681.

[9] S. Esmaeili, H. D. Dehnavi, and F. Karimzadeh, "Simultaneous reconfiguration and capacitor placement with harmonic consideration using fuzzy harmony search algorithm", Arabian Journal for Science and Engineering, vol. 39, no. 5, pp. 3859-3871, 2014. DOI: 10.1007/s13369-014-0971-4.

[10] E. S. Ali, S. M. A. Elazim, and A. Y. Abdelaziz, "Improved harmony algorithm for optimal locations and sizing of capacitors in radial distribution systems", Int. J. Electr. Power Energy Syst., vol. 79, pp. 275-284, 2016. DOI: 10.1016/j.ijepes.2016.01.015.

[11] H. S. Ramadan, A. F. Bendary, and S. Nagy, "Particle swarm optimization algorithm for capacitor allocation problem in distribution systems with wind turbine generators", Int. J. Electr. Power Energy Syst., vol. 84, pp. 143-152, 2017. DOI: 10.1016/j.ijepes.2016.04.041.

[12] M. M. Aman, G. B. Jasmon, A. H. A. Bakar, H. Mokhlis, and M. Karimi, "Optimum shunt capacitor placement in distribution system A review and comparative study", Renewable and Sustainable Energy Reviews, vol. 30, pp. 429-439, 2014. DOI 10.1016/j.rser.2013.10.002.

[13] T. Gözel and M. H. Hocaoglu, "An analytical method for the sizing and siting of distributed generators in radial systems", Electr. Power Syst. Res., vol. 79, no. 6, pp. 912-918, 2009. DOI 10.1016/j.epsr.2008.12.007.

[14] J. J. Grainger and S. H. Lee, "Optimum size and location of shunt capacitors for reduction of losses on distribution feeders", IEEE Tran. on Pow. Apparatus \& Syst., vol. PAS-100, no. 3, pp. 1105-1118, 1981. DOI: $10.1109 /$ TPAS.1981.316577.

[15] C.-S. Lee, H. V. H. Ayala, and L. Dos Santos Coelho, "Capacitor placement of distribution systems using particle swarm optimization approaches", Int. J. Electr. Power Energy Syst., vol. 64, pp. 839-851, 2015. DOI: $10.1016 /$ j.ijepes.2014.07.069

[16] H.-D. Chiang, J.-C. Wang, O. Cockings, and H.-D. Shin, "Optimal capacitor placements in distribution systems. I. A new formulation and the overall problem", IEEE Trans. Pow. Delivery, vol. 5, no. 2, pp. 634-642, 1990. DOI: 10.1109/61.53065.

[17] R. A. Gallego, A. J. Monticelli, and R. Romero, "Optimal capacitor placement in radial distribution networks", IEEE Trans. Power Syst., vol. 16, no. 4, pp. 630-637, 2001. DOI: 10.1109/59.962407.

[18] V. V. K. Reddy and M. Sydulu, "2Index and GA based optimal location and sizing of dist. system capacitors", in Proc. of 2007 IEEE Power Engineering Society General Meeting, 2007, pp. 1-4. DOI: 10.1109/PES.2007.385547.

[19] K. Prakash and M. Sydulu, "Particle swarm optimization based capacitor placement on radial distribution systems", in Proc. of 2007 IEEE Power Engineering Society General Meeting, 2007, pp. 1-5. DOI: 10.1109/PES.2007.386149.

[20] M. R. Raju, K. V. S. R. Murthy, and K. Ravindra, "Direct search algorithm for capacitive compensation in radial distribution systems", Int. J. Electr. Power Energy Syst., vol. 42, no. 1, pp. 24-30, 2012. DOI: $10.1016 /$ j.ijepes.2012.03.006.

[21] A. K. Sarma and K. M. Rafi, "Optimal selection of capacitors for radial distribution systems using plant growth simulation algorithm", International Journal of Advanced Science and Technology, vol. 30, no. 5, pp. 43-54, 2011. DOI: 10.1016/j.ijepes.2010.11.021

[22] P. Das and S. Banerjee, "Placement of capacitor in a radial distribution system using loss sensitivity factor and cuckoo search algorithm", Int. J. Sci. Res. Manage., vol. 2, no. 4, pp. 751-757, 2014.

[23] A. A. El-Fergany and A. Y. Abdelaziz, "Capacitor allocations in radial distribution networks using cuckoo search algorithm", IET Gen., Trans. \& Dist., vol. 8, no. 2, pp. 223-232, 2014. DOI 10.1049/iet-gtd.2013.0290

[24] A. A. El-Fergany and A. Y. Abdelaziz, "Artificial bee colony algorithm to allocate fixed and switched static shunt capacitors in radial distribution networks", Electric Power Components and Systems, vol. 42, no. 5, pp. 427-438, 2014. DOI: 10.1080/15325008.2013.856965.

[25] C.-T. Su, C.-F. Chang, and J.-P. Chiou, "Optimal capacitor placement in distribution systems employing ant colony search algorithm", Electric Power Components and Systems, vol. 33, no. 8, pp. 931-946, 2005. DOI: $10.1080 / 15325000590909912$.

[26] P. Das and S. Banerjee, "Optimal sizing and placement of capacitor in a radial distribution system using loss sensitivity factor and firefly algorithm", Int. J. Eng. Comput. Sci., vol. 3, no. 4, pp. 5346-5352, 2014.

[27] K. Muthukumar, S. Jayalalitha, M. Ramasamy, and C. Haricharan Cherukuri, "Optimal shunt capacitor allocation and sizing using harmony search algorithm for power loss minimization in radial distribution networks", Int. J. Dev. Res., vol. 4, no. 3, pp. 537-545, 2014.

[28] A. Sadollah, A. Bahreininejad, H. Eskandar, and M. Hamdi, "Mine blast algorithm: A new population based algorithm for solving constrained engineering optimization problems", Appl. Soft Comput., vol. 13, no. 5, pp. 2592-2612, 2013. DOI 10.1016/j.asoc.2012.11.026.

[29] A. M. Imran, M. Kowsalya, and D. P. Kothari, "A novel integration technique for optimal network reconfiguration and distributed generation placement in power distribution networks", Int. J. Electr. Power Energy Syst., vol. 63, pp. 461-472, 2014. DOI: 10.1016/j.ijepes.2014.06.011. 
[30] F. Merrikh-Bayat, "A numerical optimization algorithm inspired by the strawberry plant", arXiv, 2014.

[31] E. A. Mohamed, Al-A. A. Mohamed, and Y. Mitani, "Hybrid GMSA for optimal placement and sizing of distributed generation and shunt capacitors", Journal of Engineering Science \& Technology Review, vol. 11, no. 1, 2018. DOI: 10.25103/jestr.111.07.

[32] V. Tamilselvan, T. Jayabarathi, T. Raghunathan, and X.-S. Yang, "Optimal capacitor placement in radial distribution systems using flower pollination algorithm", Alexandria Engineering Journal, vol. 57, no. 4, pp. 2775-2786, 2018. DOI: 10.1016/j.aej.2018.01.004.

[33] H. M. Khodr, F. G. Olsina, P. M. De Oliveira-De Jesus, and J. M. Yusta, "Maximum savings approach for location and sizing of capacitors in distribution systems", Electric Power Systems Research, vol. 78 , no. 7 , pp. 1192-1203, 2008. DOI: 10.1016/j.epsr.2007.10.002.

[34] A. Y. Abdelaziz, E. S. Ali, and S. M. Abd Elazim, "Flower pollination algorithm for optimal capacitor placement and sizing in distribution systems", Electr. Power Components and Syst., vol. 44, no. 5, pp. 544-555, 2016. DOI: $10.1080 / 15325008.2015 .1117540$.

[35] M. Chakravorty and D. Das, "Voltage stability analysis of radial distribution networks", Int. J. Electr. Power Energy Syst., vol. 23, no. 2, 129-135, 2001. DOI: 10.1016/S0142-0615(00)00040-5.

[36] A. Sadollah, A. Bahreininejad, H. Eskandar, and M. Hamdi, "Mine blast algorithm for optimization of truss structures with discrete variables", Comp. \& Str., vol. 102-103, pp. 49-63, 2012. DOI: 10.1016/j.compstruc.2012.03.013.

[37] M. Shahzad, W. Gawlik, and P. Palensky, "Voltage quality index based method to quantify the advantages of optimal DG placement", in Proc. of 2016 18th International Middle East Power Systems Conference (MEPCON), 2016, pp. 759-764. DOI: 10.1109/MEPCON.2016.7836979.

[38] A. Khodabakhshian and M. H. Andishgar, "Simultaneous placement and sizing of DGs and shunt capacitors in distribution systems by using IMDE algorithm", Int. J. Electr. Pow. Energy Syst., vol. 82, pp. 599-607, 2016. DOI: 10.1016/j.ijepes.2016.04.002.

This article is an open access article distributed under the terms and conditions of the Creative Commons Attribution 4.0 (CC BY 4.0) license (http://creativecommons.org/licenses/by/4.0/). 